\title{
Comparação de parâmetros periodontais após utilização de contenção convencional $3 \times 3$ plana e contenção modificada
}

\author{
Bianca Keiko Shirasu*, Roberto Masayuki Hayacibara**, Adilson Luiz Ramos ${ }^{\star \star \star}$
}

\begin{abstract}
Resumo
Objetivo: o presente estudo teve como propósito comparar os parâmetros periodontais após a utilização de dois tipos de contenções ortodônticas fixas: contenção convencional 3x3 plana (fio ortodôntico $0,8 \mathrm{~mm}$ retilíneo fixado apenas nos caninos contralaterais) e a contenção modificada (fio ortodôntico 0,6mm com dobras permitindo o livre acesso do fio dental e fixado em todos os dentes do segmento anterior). Metodologia: quinze voluntários primeiramente utilizaram a contenção convencional por seis meses. Após um intervalo de quinze dias, foi instalada a contenção modificada, utilizada pelo mesmo período de tempo. Antes de cada fase os voluntários passaram por raspagem e alisamento radicular dos dentes e orientação de higiene bucal. Ao final de cada fase os seguintes parâmetros foram avaliados: índice de placa dentária, índice gengival e índice de cálculo dentário. Além disso, foi realizada a mensuração do cálculo no fio da contenção e todos os voluntários responderam a um questionário sobre a utilização, aceitação e conforto dos dois tipos de contenções. Resultados e Conclusões: foi observado que o índice de placa e o índice gengival foram maiores para a contenção modificada $(p<0,05)$, nas faces linguais e proximais. $\mathrm{O}$ mesmo ocorreu para o índice de cálculo nas regiões proximais $(\mathrm{p}<0,05)$. $\mathrm{O}$ índice de cálculo ao longo do fio também foi maior $(\mathrm{p}<0,05)$ para a contenção modificada. Todos os voluntários relataram que a contenção convencional foi mais confortável na utilização. Desta maneira, concluiu-se que a contenção convencional apresentou melhores resultados que a contenção modificada, de acordo com parâmetros periodontais estabelecidos.
\end{abstract}

Palavras-chave: Contenção ortodôntica fixa. Placa bacteriana. Cálculo dentário.

\section{INTRODUÇÃO}

Após a movimentação ortodôntica e tratamento da má oclusão há uma tendência de retorno dos dentes às posições iniciais. Esta tendência, chamada recidiva, pode ser eliminada com a utilização de contenções ${ }^{3,9,11,22,24}$. Assim o objetivo da contenção ortodôntica pode ser definido como: manutenção dos dentes em posições estáticas e funcionais ideais $^{20}$.O tempo de permanência da contenção está relacionado à idade do paciente, características e severidade da má oclusão, hábitos e outros fatores etiológicos, mecânica empregada e experiência clínica do ortodontista ${ }^{10}$. Como não se pode prever os casos que irão apresentar recidiva, ou o tempo

* Especialista em Periodontia. Cirurgiã-Dentista (Universidade Estadual de Maringá)

** Professor Assistente do Departamento de Odontologia da Universidade Estadual de Maringá.

*** Professor Adjunto do Departamento de Odontologia da Universidade Estadual de Maringá. 
de contenção necessário, a contenção por tempo indefinido tem sido recomendada para se manter os resultados finais alcançados com o tratamento ortodôntico $3,9,15,22,23,24$.

As contenções ortodônticas inferiores podem ser fixas ou removíveis. Há uma tendência geral dos ortodontistas optarem pela contenção fixa, devido às dificuldades de adaptação, estética e ao movimento da língua que pode levar ao desajuste do aparelho removíve ${ }^{15}$. Além disso, este tem a desvantagem de necessitar da cooperação do paciente na sua utilização e de exigir substituição quando utilizado por tempo prolongado, apesar de não interferir na higiene bucal ${ }^{7}$. Alguns autores têm sugerido muitas modificações na contenção, incluindo diferentes tipos de fios, com diferentes diâmetros e diferentes composições ${ }^{6}$. Geralmente os menores diâmetros são usados para fios flexíveis em contenções coladas a todos os dentes anteriores e os mais calibrosos para contenções fixas apenas nos caninos contralaterais ${ }^{6}$. Fios planos ou espirais podem ser utilizados para confecção das contenções mandibulares $3 \times 3^{4}$. Estudos comprovaram que contenções confeccionadas com fio espiral não acumulam mais placa bacteriana e cálculo do que contenções confeccionadas com fios planos ${ }^{3,4}$

Tem sido relatado na literatura que a maior desvantagem no uso de contenções ortodônticas fixas está na dificuldade de higienização dessas áreas, pois estas se tornam propícias ao acúmulo de placa bacteriana e conseqüentemente cálculo ${ }^{3,12}$, podendo levar à inflamação gengival e maiores danos ao periodonto ao longo do tempo ${ }^{1}$. Esta situação estaria diretamente relacionada com a utilização das contenções convencionais, principalmente, por estas dificultarem o acesso direto do fio dental às áreas próximas à gengiva. Com a finalidade de facilitar a higiene das áreas proximais, as contenções modificadas foram idealizadas e desenhadas de maneira que as dobras no fio de contenção permitam o livre acesso ao fio dental. Desta maneira, estes modelos de contenção modificada parecem facilitar a higiene desta região e têm sido indicados por apresentarem esta vantagem ${ }^{7,8,9,17}$.

Entretanto, até o momento, nenhum trabalho avaliou clinicamente a utilização desses dois tipos de contenções fixas em relação às conseqüências para o periodonto. Assim, o objetivo deste estudo foi comparar o acúmulo de placa, cálculo, inflamação gengival, cálculo ao longo do fio e conforto na mastigação conseqüentes do uso da contenção convencional e modificada durante o período de 6 meses.

\section{MATERIAL E MÉTODOS \\ Seleção dos voluntários}

Foram selecionados quinze voluntários ( 5 do gênero masculino e 10 do gênero feminino), acadêmicos do curso de Odontologia na Universidade Estadual de Maringá (UEM), para participarem deste estudo. Todos foram submetidos à anamnese e exame clínico bucal. Os critérios de inclusão foram: não estar utilizando aparelho ortodôntico durante a pesquisa, apresentar bom alinhamento nos dentes anteriores inferiores e não apresentar doença periodontal.

Os voluntários receberam um termo de consentimento livre e esclarecido, estando de acordo com as Diretrizes e Normas Regulamentadoras do Conselho Nacional de Saúde (Resolução n. 196/96). Este estudo foi iniciado após a aprovação pelo Comitê de Ética em Pesquisa em Humanos da instituição citada.

\section{Delineamento experimental}

O estudo apresentou duas fases: na primeira, todos os voluntários utilizaram a contenção convencional 3x3 plana e na segunda utilizaram a contenção modificada. O período experimental foi de 6 meses, sendo que entre as 2 fases foram observados 15 dias de intervalo. Antes de cada fase, os voluntários passaram por raspagem e alisamento radicular dos dentes anteriores inferiores e orientação de higiene bucal. Após o término de cada fase, foram realizadas as avaliações clínicas e todos os voluntários responderam a um questionário. Todas as avaliações foram realizadas por um único examinador. 


\section{Confecção das contenções}

As contenções foram confeccionadas por um único ortodontista, a partir de um modelo de gesso especial obtido de cada voluntário.

\section{Contenção plana}

A contenção plana foi confeccionada com fio ortodôntico redondo $0,8 \mathrm{~mm} / 0,032$ " e fixada apenas nos caninos inferiores contralaterais ${ }^{6}$, próximo ao terço médio-incisal, não comprometendo a estética ${ }^{16}$. Esta altura foi padronizada em $4,5 \mathrm{~mm}$ da margem cervical, por meio de um dispositivo confeccionado com silicona de adição OptosilXantopren (Confort Putty - Heraeus Kulzer, Germany), que permitiu a manutenção da contenção na boca do paciente exatamente no mesmo local

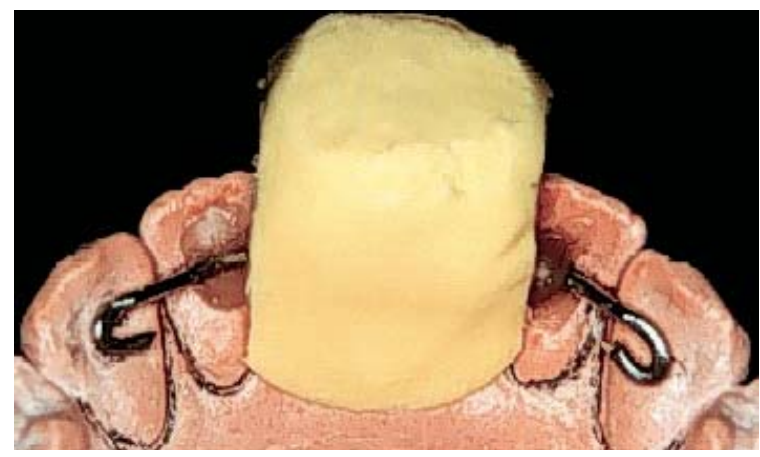

FIGURA 1- Confecção do posicionador para contenção convencional.

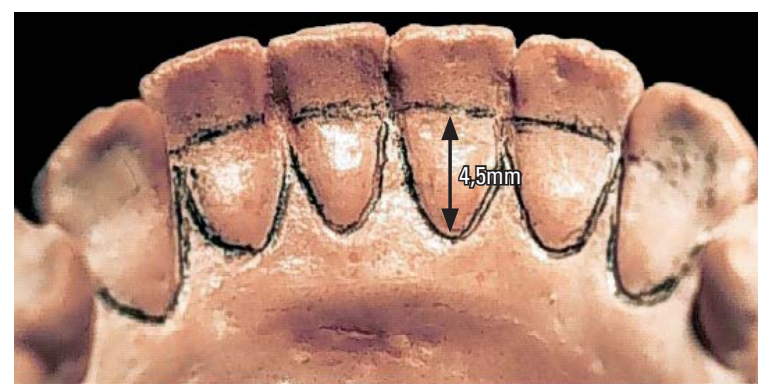

FIGURA 3 - Contorno da papila gengival para confecção da contenção modificada. do modelo de gesso durante a colagem nos caninos (Fig. 1, 2). Foi utilizada a resina composta Concise (3M - Glendora, CA/USA) para a colagem.

\section{Contenção modificada}

A contenção modificada foi confeccionada com fio redondo, 0,6mm / 0,024" e fixada de maneira que as dobras superiores ficassem $4,5 \mathrm{~mm}$ do ponto mais cervical dos incisivos (Fig. 3, 4), distantes de 0,5 a $1,0 \mathrm{~mm}$ da papila lingual ${ }^{14}$. Além disso, a porção superior da contenção, localizada no centro da face lingual de cada dente, foi deixada em contato passivo com o dente, para ser ponto de fixação (Fig. 4). O procedimento de colagem foi realizado com o auxílio do dispositivo de silicona (Fig. 5, 6) e resina composta

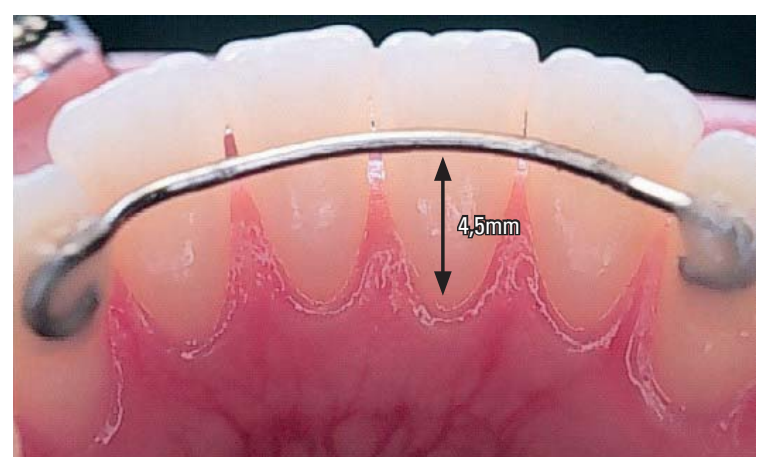

FIGURA 2 - Após a colagem da contenção convencional.

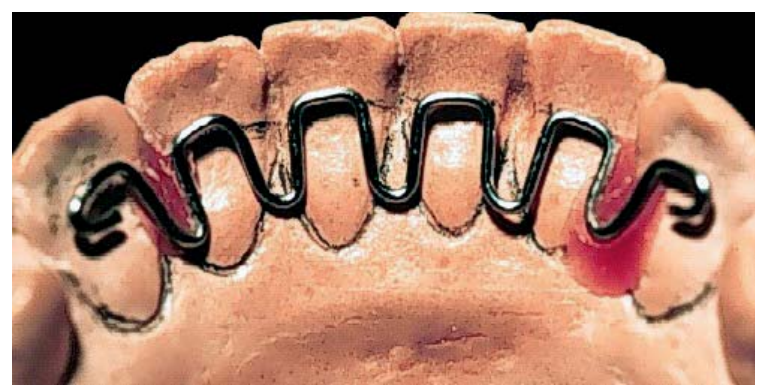

FIGURA 4 - Fixação da contenção modificada ao gesso, com cera rosa.

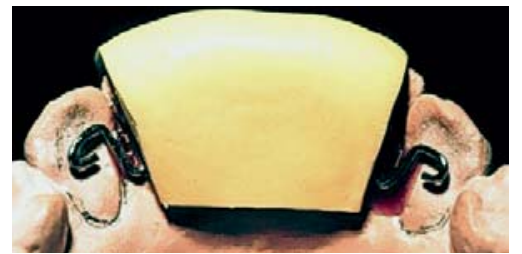

FIGURA 5 - Confecção do posicionador para contenção modificada.

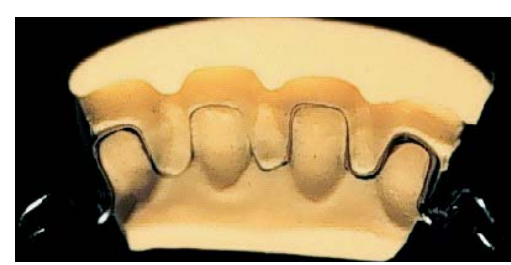

FIGURA 6 - Contenção modificada presa ao posicionador.

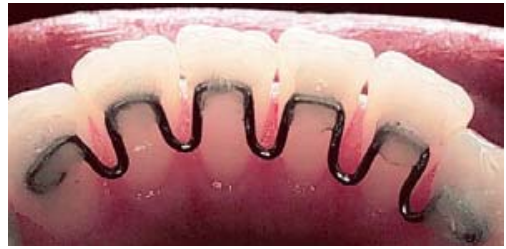

FIGURA 7 - Após a colagem da contenção modificada. 
Concise (3M - Glendora, CA - USA). O término da resina na região cervical foi mantido em zero grau, para que diminuísse a área de retenção mecânica para a placa bacteriana ${ }^{7,8}$.

\section{Avaliações clínicas}

Após cada fase, foram realizadas as avaliações periodontais dos dentes inferiores anteriores em três áreas: duas proximais e uma lingual, utilizando-se o índice de placa dentária ${ }^{21}$, índice gengival $^{18}$ e índice de cálculo dentário ${ }^{19}$. Além disso, foi realizada a mensuração do cálculo no fio da contenção ${ }^{3}$.

\section{Avaliação do comprimento do fio}

Após o término das duas fases experimentais, as contenções foram removidas, os fios foram deixados retos e os comprimentos dos fios ortodônticos foram medidos.

\section{Questionário}

Todos os voluntários responderam a um questionário após a utilização de cada contenção, para que pudessem ser analisadas ambas as contenções. Foram questionados quanto ao conforto, à facilidade de higienização e à aceitação.

\section{Análise estatística}

As médias obtidas para as variáveis índices de placa e gengival e índice de cálculo, após a utilização da contenção convencional e modificada, foram comparadas pelo teste de Friedman, considerando um nível de significância de 5\%.

\section{RESULTADOS \\ Índice de placa}

No gráfico 1 pode-se observar a média dos índices de placa dentária para as faces linguais, proximais e totais, quando utilizadas as contenções convencional ou modificada. Houve maior acúmulo de placa quando utilizada a contenção modificada, sendo os resultados estatisticamente significantes quando comparados à contenção convencional.

\section{Índice gengival}

No gráfico 2 observa-se a média do índice gengival para as faces linguais, proximais e totais, quando utilizadas as contenções convencional ou modificada. Os dados foram estatisticamente significantes, sendo que os maiores índices foram para a contenção modificada.

\section{Índice de cálculo}

A média dos índices de cálculo dentário pode ser observada no gráfico 3 . Houve diferença estatisticamente significante apenas para as faces proximais, quando comparadas as contenções convencional e modificada.

\section{Índice de cálculo ao longo do fio}

Os resultados do índice de cálculo ao longo dos fios estão representados no gráfico 4. Houve maior acúmulo de cálculo ao longo do fio da contenção modificada, sendo esta diferença estatisticamente significante em relação à convencional.

\section{Comprimento do fio}

A média do comprimento da contenção convencional foi de $2,97 \pm 0,20 \mathrm{~cm}$ e da contenção modificada $6,38 \pm 0,29 \mathrm{~cm}$, havendo uma diferença de $107 \%$ entre as contenções.

\section{Questionário}

Quanto ao conforto das contenções, 100\% dos voluntários afirmaram ser mais desconfortável a contenção modificada; $60 \%$ conseguiram uma melhor higienização quanto utilizada a contenção convencional; 53\% afirmaram a necessidade de passador de fio para a contenção modificada, enquanto $40 \%$ afirmaram esta necessidade para a contenção convencional; $67 \%$ concluíram ser melhor a contenção convencional, enquanto 33\% preferiram a modificada.

\section{DISCUSSÃO}

As contenções ortodônticas têm sido utilizadas há bastante tempo, com a finalidade de manu- 


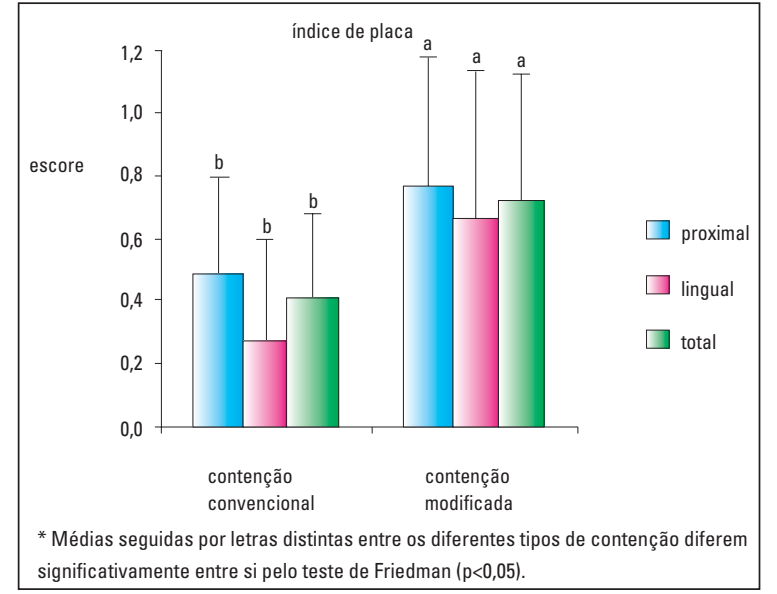

GRÁFICO 1- Médias e desvios-padrão do índice de placa nas faces proximais, linguais e totais nas contenções convencionais e modificadas.

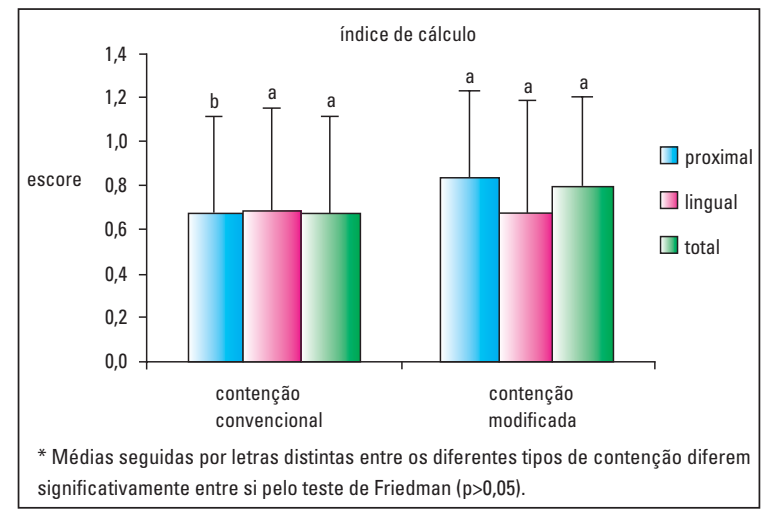

GRÁFICO 3 - Médias e desvios-padrão do índice de cálculo nas faces proximais, linguais e totais nas contenções convencionais e modificadas.

tenção dos resultados obtidos após o tratamento ortodôntico ${ }^{23}$. O modelo das contenções vem mudando com o passar dos anos ${ }^{23}$ e estão surgindo variações de contenções, com a finalidade de facilitar a higienização $0^{7,8,9,17}$.

O presente estudo mostrou que na contenção modificada ocorreu maior acúmulo de placa bacteriana nas faces proximais e linguais, quando comparada à contenção convencional (Gráf. 1). Apesar da diferença clara encontrada, nenhum escore 3 foi encontrado e foi observada pouca placa visível a olho nu, sendo a maior parte detectada ao percorrer a sonda clínica na margem gengival sobre o dente, corroborando os resultados de Artun ${ }^{3}$,

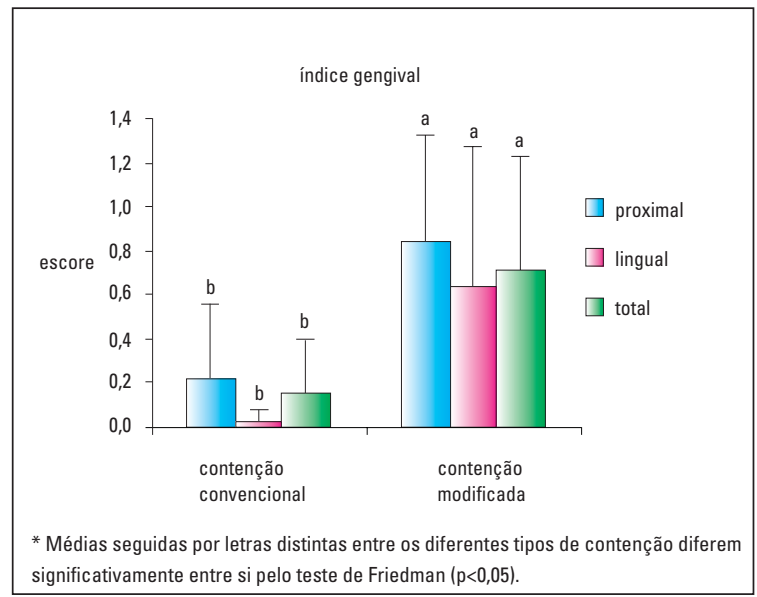

GRÁFICO 2 - Médias e desvios-padrão do índice gengival nas faces proximais, linguais e totais nas contenções convencionais e modificadas.

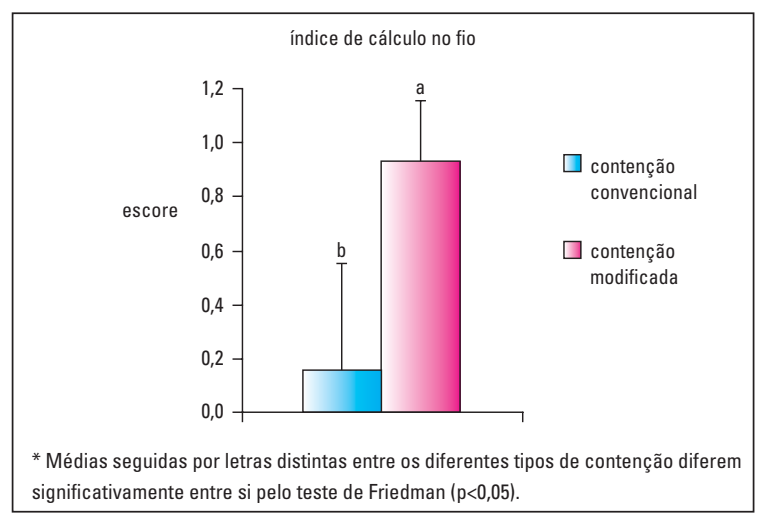

GRÁFICO 4 - Médias e desvios-padrão dos escores obtidos pelo índice de cálculo ao longo do fio das contenções convencionais e modificadas.

que avaliou o índice de placa em contenções convencionais. Os resultados encontrados podem ser justificados pelo fato de haver maior superfície do dente em contato com o fio ortodôntico na contenção modificada, favorecendo o acúmulo de placa nessas áreas. Além disso, a presença da resina no terço médio para apical em todos os dentes, na contenção modificada, também pode ter favorecido este acúmulo, estando de acordo com Artun et al. ${ }^{4}$ Estes autores sugeriram que as conseqüências periodontais decorrentes da dificuldade de manutenção da higiene poderiam ser mais severas para pacientes com contenções fixadas em todos os dentes. 
Assim como o índice de placa, o índice gengival encontrado nas faces proximais e linguais foi maior para a contenção modificada (Gráf. 2). Este resultado está coerente com os resultados do índice de placa, tendo em vista que a contenção modificada reteve mais placa bacteriana e conseqüentemente apresentou mais inflamação gengival. A maior incidência de inflamação gengival ocorreu nas faces proximais, quando comparada com as faces linguais em ambas as contenções, devido ao fato das regiões proximais dependerem exclusivamente da higiene através do fio dental, confirmando resultados obtidos em estudos que compararam outros tipos de contenções fixas ${ }^{4}$. Outro fato que pode ter favorecido maior inflamação gengival para a contenção modificada foi que, em alguns casos, a dificuldade de higienização foi agravada porque o fio ortodôntico não permitia que o fio dental chegasse completamente até a área do sulco gengival nas faces proximais.

Em relação ao índice de cálculo ao longo da margem gengival são esperados valores maiores para a contenção modificada, tendo em vista os resultados do índice de placa e índice gengival, como ocorreu nas faces proximais. É provável que essas diferenças não tenham sido encontradas para as faces linguais devido ao curto período de tempo de avaliação e também pelo fato de todos os voluntários serem acadêmicos jovens de Odontologia e apresentarem um melhor padrão de higiene bucal.

Os resultados obtidos em relação ao índice de cálculo ao longo do fio demonstraram que houve maior acúmulo de cálculo para a contenção modificada, sendo a diferença estatisticamente significante (Gráf. 4). Este fato pode ser atribuído ao comprimento do fio da contenção modificada, que é $107 \%$ maior que o comprimento do fio da contenção convencional. Além disso, o fato da contenção modificada estar colada em todos os dentes do segmento anterior pode dificultar a higienização, pois a presença da resina em cada dente pode restringir o acesso da escova dental às áreas proximais e o fio dental não pode deslizar livremente ao longo do fio de canino a canino 5 . Outro fato que pode estar associado a este resultado é a presença de ângulos ao longo da contenção modificada. Estas áreas podem ser mais retentivas e de difícil acesso à higienização, favorecendo, então, o acúmulo de cálculo ao longo desta contenção.

Em relação ao questionário feito a todos os voluntários, 60\% afirmaram conseguir higienizar melhor a região anterior quando utilizada a contenção convencional, 53\% dos voluntários acharam necessário usar o passador de fio quando utilizada a contenção modificada, enquanto apenas $40 \%$ afirmaram a necessidade do passador de fio para a contenção convencional. Estes dados podem ser atribuídos ao fato de todos os voluntários serem acadêmicos de Odontologia e terem conhecimento da necessidade de passar o fio dental até o sulco gengival. Através do questionário pode-se observar que a contenção modificada não teve boa aceitação, pois $100 \%$ dos voluntários afirmaram ser mais desconfortável, sendo que 67\% afirmaram ser melhor a contenção convencional, principalmente por acumular menos alimentos e causar menor incômodo, enquanto 33\% dos voluntários preferiram a modificada, pelo fato de terem conseguido passar o fio dental pelos pontos de contatos dentários normalmente, mesmo não chegando o fio a entrar no sulco gengival.

Zachrisson ${ }^{25}$ relatou que, em todos os tratamentos ortodônticos onde havia um apinhamento severo, se faz necessária a contenção colada em todos os dentes anteriores inferiores após o tratamento ortodôntico, para que não ocorra a recidiva. Assim sendo, é sugestivo que num próximo trabalho seja avaliada a contenção modificada com a contenção convencional plana colada também em todos os dentes.

\section{CONCLUSÃO}

De acordo com a avaliação periodontal realizada, a contenção convencional apresenta melhores resultados clínicos que a contenção modificada.

Enviado em: março de 2005 Revisado e aceito: janeiro de 2006 


\title{
Comparison of periodontal indexes after the use of conventional $3 \times 3$ plain retainer and modified retainer
}

\begin{abstract}
Aim: the purpose of the present study was to compare periodontal indexes after the use of two types of bonded fixed retainers: conventional $3 \times 3$ plain retainer (orthodontic wire $0.8 \mathrm{~mm}$, bonded to the canine teeth only) and the modified retainer $(0.6 \mathrm{~mm}$ multi strand wire, allowing free access to dental floss and bonded to all anterior teeth). Methods: a test group of fifteen patients used the conventional retainer for 6 months. After a two week interval, the modified retainer was used for another 6 months. Previous to each phase, the patients went through tooth scaling, root planing and oral hygiene orientation. At the end of each phase the dental plaque index, gingival index and dental calculus index were evaluated. Furthermore, the calculus accumulation along the retainer wire was measured and all patients answered a questionnaire about the use, acceptance and comfort of both types of retainers. Results and Conclusions: the scores for the plaque and gingival indexes were higher for the modified retainer $(p<0.05)$ in the lingual and proximal surfaces. The same occurred with the calculus index in the proximal surfaces $(p<0.05)$. The calculus along wire index also scored higher $(p<0.05)$ for the modified retainer. All patients described the use of the conventional retainer as being more comfortable. Therefore, it was concluded that the conventional retainer is a better treatment choice than the modified retainer.
\end{abstract}

Key words: Bonded fixed retainer. Plaque. Dental calculus.

\section{REFERÊNCIAS}

1. ALSTAD, S.; ZACHRISSON, B. U. Longitudinal study of periodontal condition associated with orthodontic treatment in adolescents. Am J Orthod, St. Louis, v. 76, p. 277-286, 1979.

2. ARTUN, J.; ZACHRISSON, B. U. Improving the handling properties of a composite resin for direct bonding. Am J Orthod, St. Louis, v. 81, p. 269-279, Apr. 1982.

3. ARTUN, J. Caries and periodontal reactions associated with long-term use of different types of bonded lingual retainers. Am J Orthod, St. Louis, v. 86, p. 112-118, 1984.

4. ARTUN, J. et al. Hygiene status associated with different types of bonded, orthodontic canine-to-canine retainers. J Clin Periodontol, Copenhagen, p. 89-93, 1987.

5. ARTUN, J.; SPADAFORA, A. T.; SHAPIRO, P. A. A 3-year follow-up study of various types of orthodontic canine-to-canine retainers. Eur J Orthod, Oxford, v. 19, p. 501-509, 1997

6. BEARN, D. R. Bonded orthodontic retainers: a review. Am J Orthod Dentofacial Orthop, St. Louis, v. 108, p. 207-213, 1995.

7. BICALHO, J. S.: BICALHO, K. T. Descrição do método de contenção fixa com livre acesso do fio dental. R Dental Press Ortodon Ortop Facial, Maringá, v. 6, p. 97-104, set./out. 2001.

8. BICALHO, J. S.; BICALHO, K. T. Descrição do método de contenção fixa com livre acesso do fio dental. R Clin Ortodon Dental Press, Maringá, v. 1, p. 9-13, fev./mar. 2002.

9. CERNY, R. Permanent fixed lingual retention. J Clin Orthod Boulder, v. 35, p. 728-732, 2001

10. CIRUFFO, P.; NOUER, D. Contenção pós-tratamento ortodôntico. J Bras Ortodon Ortop Maxilar, Curitiba, v. 2, p. 5-11, 1997.

11. DAHL, E. H.; ZACHRISSON, B. U. Long-term experience with direct-bonded lingual retainers. J Clin Orthod, Boulder, v. 25 , p. 619-630, 1991

12. GORELICK, L: GEIGER A. M. GWINNETT A J. Incidence of white spot formation after bonding and banding. Am J Orthod, St. Louis, v. 81, p. 93-98, 1982.

13. HEIER, E. E. et al. Periodontal implications of bonded versus removable retainers. Am J Orthod, St. Louis, v. 112, p. 607-616, 1997.
14. JANSON, G. R. P. et al. Nickel hipersensitivity reaction before, during, and after orthodontic therapy. Am J Orthod Dentofacial Orthop, St. Louis, v. 113, p. 655-660, 1998.

15. KAPLAN, H. The logic of modern retention procedures. Am J Orthod Dentofacial Orthop, St. Louis, v. 93, p. 325-340, 1988.

16. KNIERIN, R. W. Invisible lower cuspid to cuspid retainer. Angle Orthod, Appleton, v. 43, no. 2, p. 218-220, Apr. 1973.

17. LEW, K. K. K. Direct-bonded lingual retainer. J Clin Orthod, Boulder, v. 23, p. 490-491, 1989

18. LÖE, H.; SILNESS J. Periodontal disease in pregnancy I. Prevalence and severity. Acta Odontol Scand, Oslo, v. 21, p. 533551,1963

19. RAMFJORD, S. P. Indices for prevalence and incidence of periodontal disease. J Periodontol, Copenhagen, v. 30, p. 51-59, 1959.

20. RIEDEL, R. A. An analysis of dento facial relationships. Am J Orthod, St. Louis, v. 43, no. 2, p. 103-119, Fev. 1957.

21. SILNESS J.; LÖE H. Periodontal disease in pregnancy. II. Correlation between oral hygiene and periodontal condition. Acta Odontol Scand, Oslo, v. 22, p. 112-135, 1964

22. ZACHRISSON, B. U. Clinical experience with direct bonded orthodontic retainers. Am J Orthod, St. Louis, v. 71, p. 440-448, 1977

23. ZACHRISSON, B. J. Third-generation mandibular bonded lingual 3-3 retainer. J Clin Orthod, Boulder, v. 29, p. 39-48, 1995

24. ZACHRISSON, B. U. The bonded lingual retainer and multiple spacing of anterior teeth. J Clin Orthod, Boulder, v. 17, p. 838$844,1983$.

25. ZACHRISSON, B. U. Aspectos importantes da estabilidade a longo prazo. Rev Clin Ortodon Dental Press, Maringá, v. 4, p. 90-121, 1997.

\section{Endereço para correspondência}

Roberto Masayuki Hayacibara

Av. Paraná, 242/conj. 1904/1905

CEP: $87.013-070$ - Maringá/PR

E-mail: hayacibara@wnet.com.br 